\title{
Promoting work ability and well-being in hospital nursing: The interplay of age, job control, and successful ageing strategies
}

\author{
Andreas Müller*, Matthias Weigl, Barbara Heiden, Jürgen Glaser, and Peter Angerer \\ Institute and Outpatient Clinic for Occupational, Social and Environmental Medicine; Ludwig-Maximilians- \\ University Munich; Ziemssenstr. 1, 80336 Munich, Germany
}

\begin{abstract}
Previous research shows that work ability of nurses decreases with age. In our study we therefore addressed the following questions: Do successful ageing strategies at work in terms of selection, optimization, and compensation (SOC) support the work ability of nurses? Does SOC mediate the relationship between job control (i.e., decision opportunities at work) and work ability? Does the mediation differ between age-groups? 438 nurses (Age Range 21-63 years) completed a questionnaire in the course of an employee survey. Results show that SOC is positively related with work ability. The positive effect of job control on work ability is significantly mediated by SOC. There are stronger mediating effects for elder nurses than for younger nurses. Results indicate that the interplay of job control and SOC at work helps to maintain the work ability of nurses in nursing care.
\end{abstract}

Keywords: demographic change; ageing; work ability; selection, optimization, compensation; job control

\section{Introduction}

\subsection{Background}

Research indicates that work ability of nurses - i.e. the individual physical and psychological capability to perform his/her work [32] - decreases with age [7]. Poor work ability in turn was shown to be closely related to diminished mental and physical well-being, emotional exhaustion, intention to leave the nursing job, and disability $[2,7,8]$. Thus, against the background of the ageing healthcare workforce in Western countries and in order to master the increasing demand in delivery of healthcare, it is of utmost importance to maintain and to promote the work ability of nurses [7,29].

\subsection{Goal of the study}

Previous research mainly focused on the relation between working conditions and work ability [33]. So far, studies on work ability widely neglected important contributions from developmental psychology regarding individual life management strategies of 'successful ageing' in terms of selection, optimization, and compensation (SOC) [4]. Moreover there is lacking evidence about the effects of the interplay between working conditions and the application and effects of SOC at work [27]. The empirical verification of such a relationship may foster theoretical development of occupational life-span models in healthcare work and adequate workplace interventions to promote the work ability in nurses.

Thus, the goal of this study is to investigate the interplay between the use of SOC at work, age, and working conditions (job control) in determining work ability in nurses.

\footnotetext{
* Corresponding author. Email: andreas.mueller@med.lmu.de; Phone: +49-89-5160-5312; Fax: +49-89-5160-5306.
} 


\subsection{The model of selection, optimization, and compensation (SOC)}

SOC is considered as fundamental individual, lifemanagement strategy in competence maintenance in the course of ageing [27]. According to Freund and Baltes [14] the three SOC dimensions can be defined as follows: Selection refers to goal setting and prioritization, based on personal motives and preferences (elective selection) or due to perceived loss of internal or external resources (loss-based selection). It is assumed that the focus on specific goals - in contrast to dividing ones energy among multiple goals organizes individual behavior, directs personal development, and creates the feeling of purpose and meaning in ones life. Optimization involves the permanent obtainment, improved and coordinated use of individual means to pursue selected goals. Compensation specifically addresses the question how people are maintaining a desired level of functioning in the face of loss of available means. Thus compensation involves the acquisition and application of alternative individual means or use of external or technological aid to substitute lost means and to maintain a desirable level of functioning in goal attainment.

Accordingly previous research emphasized the benefits of SOC at work on favorable individual outcomes like performance [3,39], competence maintenance [1], focus on opportunities, i.e. positive expectations about future options at work [41], job satisfaction and well being $[37,38]$.

\subsection{Hypotheses}

In line with the study goals we derive the following hypotheses.

Hypothesis 1: Job control is positively related to work ability. Job control refers to the extent to which an employee's work allows discretion to schedule tasks, make decisions, and choose methods to perform tasks [16,35]. A large body of research emphasizes the crucial role of job control that is conducive to employee's performance, satisfaction, and wellbeing $[9,19,34]$. In regard to work ability, a comprehensive review of van den Berg et al. [33] found a positive association of job control and work ability in three out of four studies.

Hypothesis 2: The use of SOC at work is positively related to work ability. Employees who are applying SOC at work may use their individual resources more efficiently and may therefore cope better with detri- mental job conditions or losses in individual capabilities, e.g., physical strength, information processing ability [27]. Likewise, individuals with a lack of SOC may fail in adapting to changing capabilities and resources and therefore experience diminished work ability.

Hypothesis 3: Job control is positively related to the use of SOC at work. The use SOC at work like prioritizing tasks (i.e., selection) or developing alternative means to perform tasks (i.e., compensation) might benefit from enhanced job control, such as a broader selection of job tasks or discretion of alternate means or methods of job task execution [1]. Conversely, jobs with less control might provide employees limited opportunities to apply SOC.

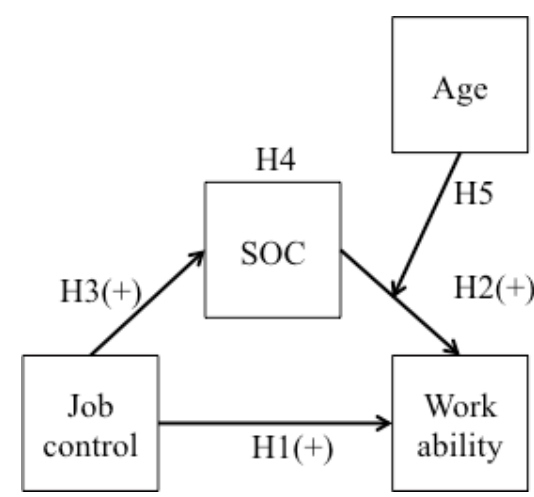

Fig. 1 - The proposed model and hypotheses $(\mathrm{H})$ of work ability, job control, age, and strategies of selection, optimization, and compensation (SOC)

Hypothesis 4: The use of SOC at work mediates the relationship between job control and work ability, such as there is a indirect effect of job control on work ability through SOC. Theories of human action regulation emphasize that objective working conditions affect individuals not until these conditions are psychological represented $[12,15]$. More specifically, not only the mere presence of job control should be relevant for work ability, but the effective individual use of job control in terms of SOC.

Hypothesis 5: The indirect effect of job control through SOC on work ability becomes stronger with age. SOC allows for adaptation, and maintained functioning in face of age-related losses [27]. Thus, SOC at work should help particularly elder employees to maintain work ability and remain healthy and capable in their jobs. Therefore, in elder employees the indirect effect of job control through use of SOC 
on work ability should be more relevant compared to younger age groups.

To sum it up, the overall research model can be characterized as 'moderated mediation' model [26]. First, it is hypothesized that the independent variable 'job control' determines the dependent variable 'work ability' through the mediator variable 'SOC' (mediation-hypothesis H4). Second, it is assumed that the strengths of the indirect effect of job control through SOC on work ability depends on effects of 'age', i.e. the path of SOC on work ability is moderated by age (moderated mediation-hypothesis H5). Figure 1 illustrates the proposed research model.

\section{Method}

\subsection{Procedure}

Data was gathered in the course of a cross-sectional employee survey in a German University Hospital. Nurses received a personally addressed envelope with the questionnaire, detailed information about the study, and a declaration of consent. The nurses were asked to give their written informed consent for the employee survey. Participation was voluntary.

\subsection{Participants}

438 out of 953 nurses (participation rate $46.0 \%$ ) working in 42 wards completed a questionnaire. 366 $(83.6 \%)$ nurses were female and 71 male $(16.2 \% ; 1$ missing). Age ranged from 21 to 63 years with an average of 38.5 years (standard deviation, $\mathrm{SD}=$ 11.2). 190 nurses were $<35$ years $(43.7 \%)$, 111 between 35 and 44 years $(25.5 \%)$, and $134 \geq 45$ years $(30.8 \%$, missing $\mathrm{n}=3)$. The average professional tenure was 18.1 years $(\mathrm{SD}=10.9) .238$ nurses $(54.5 \%)$ came from intensive care units, 85 (19.5\%) from the operating room, 68 (15.5\%) from anesthesia units, 39 $(8.9 \%)$ from general wards, and $7(1.6 \%)$ male nurses were exclusively responsible for patient transfer in the operating rooms (missing $\mathrm{n}=1$ ).

\subsection{Measures}

Job control was assessed with nine items of a German self-report instrument for work analysis in hospitals (e.g., "This work allows for decisions on which work methods one pursues") [6]. The instrument is well-validated, repeatedly used in German speaking countries, and especially adapted to health-care professions $[18,36]$. All items used a 5point Likert scale from $1=$ "not at all" to $5=$ "to a very great extent." Cronbach's alpha was $\alpha=.94$.

$S O C$ was assessed with a nine-item 'SOC in nursing scale' developed by Müller et al. [23]. Items were developed on the basis of interviews with elder nurses $\geq 45$ years, about their coping behavior at work. Interview content was coded on the basis of SOC definitions by Freund and Baltes [14]. Three items for each of the three SOC dimensions were selected (e.g. selection: "I concentrate on the most important tasks to do my job well"). Item selection was based on consensus by involved nursing experts and work psychology professionals. Substantial positive correlations of $\mathrm{r}=.39$ with the original 12 -item SOC short scale $[5,14]$ point to the construct validity of the scale. Cronbach's alpha was $\alpha=.76$.

Work ability was measured with an abbreviated German version of the Work Ability Index Scale (WAI) [17]. The original scale was developed by Tuomi, Ilmarinen, and colleagues [32]. The two items applied in this study cover the second dimension of the WAI. It assesses the perceived work ability in relation to physical and psychological job demands (WAI Dimension 2). This dimension is closely related to the overall work ability [22]. Studies show that shortened, abbreviated measures of the WAI are highly correlated to the overall WAI-score as well as they are predictive to well-being outcomes [2]. Items used a 5-point Likert scale ranging from 1="very poor" to 5="very good". Cronbach's alpha of the scale was $\alpha=.64$.

Information on nurses' age was based on the employee survey. We asked for life years with a single item.

Covariates: Information on all control variables was based on questionnaire-based self-report data. Participants indicated gender $($ male $=0$, female $=1)$ and job-tenure in years. Further control variables were supervisor position and exercise: Supervisor position was assessed with one single item (answer options $(0=$ no supervisor; $1=$ supervisor $)$. We controlled for supervisor positions, because higher level positions are associated with higher work ability [11]. Exercise was measured as a single item: "How often are you doing physical activities for at least $20 \mathrm{~min}$ utes, that make you at least a little bit sweat or short of breath (e.g., sports, hiking, dancing)?" This item used a 5-point scale ranging from 1="daily" to $5=$ "never". Studies show that lack of leisure-time physical activities is associated with lower work ability [33]. 
Table 1

Means (M) standard deviations (SD), and intercorrelations of study variables

\begin{tabular}{|c|c|c|c|c|c|c|c|c|c|}
\hline & $M$ & $S D$ & 01. & 02. & 03. & 04. & 05. & 06. & 07. \\
\hline 01. Work ability & 3.94 & .68 & & & & & & & \\
\hline 02. Gender & .84 & .37 & -.01 & & & & & & \\
\hline 03. Job tenure & 18.16 & 10.95 & -.09 & .07 & & & & & \\
\hline 04. Supervisor position & .17 & .38 & .04 & -.03 & $.30 * *$ & & & & \\
\hline 05. Exercise & 2.98 & 1.00 & $-.17 * *$ & .02 & -.08 & $-.10 *$ & & & \\
\hline 06. Job control & 3.19 & .82 & $.18^{* *}$ & $.13^{* *}$ & .00 & $.10^{*}$ & -.03 & & \\
\hline 07. Age & 38.53 & 11.25 & $-.12 *$ & -.01 & $.90 * *$ & $.25 * *$ & -.07 & -.07 & \\
\hline 08. SOC & 3.62 & .54 & $.25^{* *}$ & -.03 & $.22 * *$ & .08 & $-.24 * *$ & $.19 * *$ & $.22 * *$ \\
\hline
\end{tabular}

Note. ${ }^{*} p<.05 ; * * p<.01$.

\subsection{Data analyses}

All data was checked for correctness and implausible values. Initial descriptive statistical analyses were followed by the computation of two mediation models: First, all main effects (Hypothesis 1-3) and the indirect (mediator) effect without moderator (Hypothesis 4) were computed with a method proposed by Preacher and Hayes [25]. Mediation was formally tested with bootstrapped estimates of the indirect effect of job control on work ability through SOC. This nonparametric approach was chosen because bootstrapped estimates are robust against violation of the normal distribution of variables [28]. Covariates controlled for effects between the independent variable and the mediator and between the mediator and the dependent variable.

Second, a method proposed by Preacher, Rucker, and Hayes [26] was used to test for moderated mediation (Hypothesis 5). The method estimates the effect of the dependent variable through a mediator variable on the dependent variable under the condition of a moderator (conditional indirect effect). Bootstrap confidence intervals for conditional indirect effects at specific values of the moderator age (mean \pm 1 standard deviation) were computed to expose the direction of the moderation. All analyses were performed with SPSS 19.0.

\section{Results}

Descriptive statistics and intercorrelations of study variables are shown in Table 1. Employees' work ability shows the highest positive correlations with SOC followed by job control. There are negative associations of work ability with exercise and age.
Age is positively related to $\mathrm{SOC}$, indicating that elder employees report more SOC.

Table 2

Mediation of job control on work ability through SOC moderated by age

\begin{tabular}{|c|c|c|c|c|}
\hline a) Direct effects & $B$ & $S E$ & $t$ & $p$ \\
\hline Job control on work ability (H1) & .15 & .04 & 3.85 & .00 \\
\hline SOC on work ability $(\mathrm{H} 2)^{a}$ & .28 & .06 & 4.52 & .00 \\
\hline \multirow[t]{2}{*}{ Job control on SOC $(\mathrm{H} 3)^{a}$} & .13 & .03 & 4.14 & .00 \\
\hline & & & \multicolumn{2}{|c|}{$\begin{array}{c}\text { Bootstrapping } \\
95 \% \text { CI } \\
\end{array}$} \\
\hline b) Mediation & $B$ & $S E$ & Lower & Upper \\
\hline $\begin{array}{l}\text { Job control on work ability } \\
{\text { through SOC }(\mathrm{H} 4)^{\text {a }}}\end{array}$ & .04 & .01 & .01 & .07 \\
\hline c) Moderated mediation & $B$ & $S E$ & $t$ & $p$ \\
\hline SOC $x$ age $(H 5)^{a}$ & .02 & .01 & 2.71 & .01 \\
\hline
\end{tabular}

Table 2 summarizes the results of the moderated mediation model. All hypothesized direct effects are significant (cf., Table 2a): There is a significant positive effect of job control on work ability, as well as of SOC on work ability and of job control on SOC. These findings corroborate Hypotheses 1, 2, and 3.

Bootstrap estimates of the $95 \%$ confidence interval of the indirect effect of job control on work ability through SOC do not include 0 (cf., Table 2b). Thus SOC significantly mediates the effect of job control on work ability, supporting Hypothesis 4. The direct effect of job control on work ability remains significant under control of the mediator SOC $(B=.11$, $S E=.40, t=2.96, p=.01$, not listed in Table 2). Thus, 
there are effects of job control on work ability that cannot be explained by the mediation of SOC.

Table 3

Conditional indirect effects of job control on work ability through SOC at age $=$ mean $\pm 1 \mathrm{SD}$

\begin{tabular}{|c|c|c|c|c|}
\hline \multirow[b]{2}{*}{ age } & \multirow[b]{2}{*}{$B$} & \multirow[b]{2}{*}{$S E$} & \multicolumn{2}{|c|}{$\begin{array}{c}\text { Bootstrapping } \\
95 \% C I\end{array}$} \\
\hline & & & Lower & Upper \\
\hline 27.3 years & .01 & .01 & -.01 & .04 \\
\hline 38.5 years & .03 & .01 & .01 & .06 \\
\hline 49.7 years & .05 & .02 & .02 & .09 \\
\hline
\end{tabular}

A significant two-way interaction between SOC and age on work ability indicates that the indirect effect of job control on work ability through SOC is moderated by age (Table $2 \mathrm{c}$ ).

Results in Table 3 on the conditional indirect effects of job control on work ability through SOC reveal the direction of the moderation at pre-specified age values: by default the effect of the mean age (38.5 years) and one standard deviation below (27.3 years) and above the mean (49.7 years) are displayed. The conditional indirect effects of job control on work ability through SOC become stronger with age. Bootstrap estimates of the $95 \%$ confidence interval of the conditional indirect effects show that the effect at 27.3 years is non significant, whereas the effects at 38.5 years and 49.7 years are statistically significant. These findings confirm Hypothesis 5.

\section{Discussion}

This study aimed to investigate the interplay between individual life management strategies of 'successful ageing' in terms of selection, optimization, and compensation (SOC) [4], age, and job control in determining work ability in nurses. Work ability indicates employees' individual capabilities to perform his or her work in respect to their physiological and psychological job demands [32]. It can be therefore conceived as an important criterion of successful aging at work. However, previous studies did not answer the question, if employees use life management strategies - like SOC - to maintain their work ability. Moreover the interplay between SOC, age, and working conditions - as in our case job control - in maintaining work ability is not studied yet.
Results of the present study on the positive effect of job control on work ability replicate previous findings on job control as a crucial resource for work ability [33].

Moreover, results confirm a positive association of use of SOC and work ability. This finding shows for the first time that strategies of 'successful ageing' like setting priorities at work (selection), continuously improving job task execution (optimization), and balancing out losses (compensation) are conducive to the physical and psychological capability of nurses to perform their work. With that, the results confirm the growing evidence on the benefits of SOC at work on favorable individual outcomes [1,3,37$39,41]$ and exceed previous research on maintaining work ability that so far widely ignored the importance of individual life management strategies of 'successful ageing'. Because previous studies show that diminished work ability increases the risk of early exit from the nursing job [8], the improvement of work ability by SOC may contribute to master the challenges of the nursing shortage and of the increasing demand in delivery of health care [29].

Results further point to a positive relation between job control and SOC, such as higher job control is associated with more SOC use at work. This finding extends the existing knowledge on the relation between contextual features and the use of SOC at work [27]: So far studies on SOC at work almost exclusively indicated that that people who are applying SOC cope better with critical working conditions, because they may use available resources more efficiently [40,41]. The observed positive effect of job control on SOC suggests that the use of SOC at work requires favorable working conditions. This finding supports assumptions that the use of SOC is resource demanding itself and therefore should benefit from enhanced environmental resources at work [13]. The finding further demonstrates the importance of favorable job design for successful ageing at work, i.e., creating enhanced job control at work.

Beyond that, the study indicates that the positive effect of job control on work ability is partly mediated by SOC, and that this mediation is moderated by age, such as there are stronger mediating effects for elder than for younger nurses. The observed mediation is in line with action theoretical assumptions on the interplay between objective working conditions and psychological redefinitions of these conditions and the effects of this interplay on individual outcomes $[12,15]$.

Finally, the observed moderated mediation provides some empirical hints for the assumption that 
high job control allows elder workers to better utilize and transfer their knowledge and work experience [21]. In line with that assumption the results suggest that job control can help elder nurses through the use of SOC to maintain important capacities and competencies at work despite experiencing age-related losses. Thus, the study also supports one of the basic propositions of the SOC model [4].

The study has several limitations: First, it uses a cross-sectional design which allows only a preliminary evaluation of the hypothesized cause-effect relations. Thus, although there is a sound theoretical basis for the suggested directions between the study variables, reciprocal effects cannot be ruled out. For example, beside the assumed effect of SOC on work ability it is possible that nurses with better work ability, i.e., with enhanced individual resources, are capable to employ more SOC, because SOC is resourceful itself [13]. Further, the validity of observed age effects may be limited due to differences between birth cohorts (e.g., because of societal changes) and not necessarily reflect ageing development [30]. Moreover, a potential healthy worker effect might have occurred, i.e., nurses with impaired work ability might have retired earlier and comparatively healthier and fitter nurses took part in the study [8]. Thus, future studies should apply cross-lagged panel designs that allow for testing reciprocal effects between study variables [42] and use long term longitudinal cohort designs to distinguish between cohort differences and ageing development as well as to overcome healthy worker effects.

Second, the study exclusively used self-report data. Thus a common method variance might lead to an inflation of observed associations [24]. However, altogether there seems only limited empirical evidence that a common method itself produces systematic variance that inflates associations to a significant degree [31]. Nevertheless, it is desirable to replicate the present results by applying multi-method designs, such as using for instance supervisor ratings, job descriptions, observational data to assess job control or conducting standardized medical examinations of work ability.

Third, the data is based on a convenience sample, which limits the generalizability of our results. However, the sample is similar to the typical German workforce in nursing regarding gender structure and job-tenure $[10,20]$.

The study has also several practical implications: Generally, the study suggests that nurses should be acquainted and trained with the SOC model. SOC trainings should focus on the participative development and work-related application of adequate SOC behaviors to cope with individually relevant job demands. The SOC training could further support the implementation of SOC into practice and accompany the implementation over a certain time period. In addition, such behavior-oriented SOC trainings at work should be supplemented with job design interventions that enhance job control. There are several reasons for that suggestion: The results on the direct effects of SOC and job control on work ability indicate that SOC trainings as well as job design interventions that increase job control should each have a unique positive effect on work ability. Moreover, the findings also point to synergistic effects of both intervention approaches: On the one hand, job control seems to be an important precondition for the application of SOC at work and should therefore contribute to the effectiveness of SOC trainings. On the other hand, the observed mediation indicates that the positive effects of job control are partly effective through SOC use. Thus SOC trainings can also supplement the effectiveness of job design interventions.

\section{Authors note}

This research was supported by the German Research Foundation (Deutsche Forschungsgemeinschaft, DFG): MU 3079/1-1 and the Munich Center of Health Sciences. The project is part of the DFG priority program 1184 "Age-differentiated work systems". Approval to conduct research related to this paper was obtained from the Ethics Committee of the Faculty of Medicine, Munich University (No 25609). The authors would like to thank Helga Asenbauer, Martina Bürger, Ines Englmann, and Dana Lippert for helping conducting this study.

\section{References}

[1] J.D. Abraham and R.O. Hansson, Successful aging at work: an applied study of selection, optimization, and compensation through impression management, Journals of Gerontology: Series B, Psychological Sciences and Social Sciences 50 (1995), 94-103.

[2] L. Ahlstrom, A. Grimby-Ekman, M. Hagberg and L. Dellve, The work ability index and single-item question: associations with sick leave, symptoms, and health-a prospective study of women on long-term sick leave, Scandinavian Journal of Work, Environment \& Health 36 (2010), 404412.

[3] J.K. Bajor and B.B. Baltes, The relationship between selection optimization with compensation, conscientiousness, 
motivation, and performance, Journal of Vocational Behavior 63 (2003), 347-367.

[4] P.B. Baltes and M.M. Baltes, Psychological perspectives on successful aging: The model of selective optimization with compensation, in: Successful aging: Perspectives from the behavioral sciences, P.B. Baltesand M.M. Baltes, (Eds.), Cambridge University Press, New York, 1990, pp. 1-34.

[5] P.B. Baltes, M.M. Baltes, A.M. Freund and F.R. Lang, The measure of selection, optimization, and compensation (SOC) by self-report, Max Planck Institute for Human Development, Berlin, 1999.

[6] A. Büssing and J. Glaser, Das Tätigkeits- und Arbeitsanalyseverfahren für das Krankenhaus - Selbstbeobachtungsversion (TAA-KH-S) [Work analysis instrument for hospitals - Self report version (TAA-KH-S)], Hogrefe, Göttingen, 2002.

[7] D. Camerino, P.M. Conway, B.I.J.M. Van der Heijden, M Estryn-Behar, D. Consonni, D. Gould and H.-M. Hasselhorn, Low-perceived work ability, ageing and intention to leave nursing: A comparison among 10 European countries, Journal of Advanced Nursing 56 (2006), 542-552.

[8] D. Camerino, P.M. Conway, B.I.J.M. van der Heijden, M. Estryn-Béhar, G. Costa and H.-M. Hasselhorn, Agedependent relationships between work ability, thinking of quitting the job, and actual leaving among Italian nurses: a longitudinal study, International Journal Of Nursing Studies 45 (2008), 1645-1659.

[9] A.H. de Lange, T.W. Taris, M.A.J. Kompier, I.L.D. Houtman and P.M. Bongers, 'The very best of the millennium' Longitudinal research and the demand-control-(support) model, Journal of Occupational Health Psychology 8 (2003), 282.

[10] Federal Statistical Office of Germany, Statistical Yearbook 2010, Federal Statistical Office of Germany, Wiesbaden, 2010.

[11] T. Feldt, K. Hyvonen, A. Makikangas, U. Kinnunen and K. Kokko, Development trajectories of Finnish managers' work ability over a 10-year follow-up period, Scandinavian Journal of Work Environment \& Health 35 (2009), 37-47.

[12] M. Frese and D. Zapf, Action as the core of work psychology: A German approach., in: Handbook of industrial and organizational psychology, M.D. Dunnette, L.M. Houghand H.C. Triandis, (Eds.), Consulting Psychologists Press, Palo Alto, CA, 1994, pp. 271-340.

[13] A.M. Freund, Age-Differential Motivational Consequences of Optimization Versus Compensation Focus in Younger and Older Adults, Psychology and Aging 21 (2006), 240252.

[14] A.M. Freund and P.B. Baltes, Life-management strategies of selection, optimization and compensation: Measurement by self-report and construct validity, Journal of Personality and Social Psychology 82 (2002), 642-662.

[15] W. Hacker, Action Regulation Theory - A practical tool for the design of modern work processes? , European Journal of Work and Organization Psychology 12 (2003), 105-130.

[16] J.R. Hackman and G.R. Oldham, Motivation through the design of work: Test of a theory., Organizational Behavior and Human Performance 16 (1976), 250-279.

[17] H.-M. Hasselhorn and G. Freude, Der Work Ability Index [The Work Ability Index], Wirtschaftsverlag, NW, Bremerhaven, 2007.

[18] S. Hornung, D.M. Rousseau, J. Glaser, P. Angerer and M. Weigl, Beyond top-down and bottom-up work redesign: Customizing job content through idiosyncratic deals, Journal of Organizational Behavior 31 (2010), 187-215.
[19] S.E. Humphrey, J.D. Nahrgang and F.P. Morgeson, Integrating motivational, social, and contextual work design features: A meta-analytic summary and theoretical extension of the work design literature, Journal of Applied Psychology 92 (2007), 1332.

[20] M. Isfort, F. Weidner and et al., Pflege-Thermometer 2009. Eine bundesweite Befragung von Pflegekräften zur Situation der Pflege und Patientenversorgung im Krankenhaus. [Nursing-Thermometer 2009. A nationwide survey of nuses to to the situation of care and patient care in hospitals], German Institute of Applied Nursing Research, Köln, 2009.

[21] R. Kanfer and P.L. Ackerman, Aging, Adult Development, and Work Motivation, Academy of Management Review 29 (2004), 440-458.

[22] P. Martus, O. Jakob, U. Rose, R. Seibt and G. Freude, A comparative analysis of the Work Ability Index, Occupational Medicine-Oxford 60 (2010), 517-524.

[23] A. Müller, M. Weigl, B. Heiden, J. Glaser and P. Angerer, The relationship between job-specific strategies of selection, optimization, and compensation (SOC) in nursing and the work ability of nurses: Qualitative and cross-sectional quantitative findings., Paper submitted for publication (2011).

[24] P.M. Podsakoff, S.B. MacKencie, J.-Y. Lee and N.P. Podsakoff, Common method biases in behavioral research: A critical review of the literature and recommended remedies, Journal of Applied Psychology 88 (2003), 879-903.

[25] K.J. Preacher and A.F. Hayes, Asymptotic and resampling strategies for assessing and comparing indirect effects in multiple mediator models, Behavior Research Methods 40 (2008), 879-891.

[26] K.J. Preacher, D.D. Rucker and A.F. Hayes, Addressing moderated mediation hypotheses: Theory, methods, and prescriptions, Multivariate Behavioral Research 42 (2007), 185-227.

[27] M. Riediger, S.-C. Li and U. Lindenberger, Selection, Optimization, and Compensation as Developmental Mechanisms of Adaptive Resource Allocation: Review and Preview, in: Handbook of the Psychology of Aging. 6th Edition, J.E. Birrenand K.W. Schaie, (Eds.), Elsevier, Amsterdam, 2006, pp. 289-314.

[28] P.E. Shrout and N. Bolger, Mediation in experimental and nonexperimental studies: New procedures and recommendations, Psychological Methods 7 (2002), 422-445.

[29] S. Simoens, M. Villeneuve and J. Hurst, Tackling Nurse Shortages in OECD Countries, OECD, Directorate for Employment, Labour and Social Affairs, 2005.

[30] K.W. Smola and C.D. Sutton, Generational differences: revisiting generational work values for the new millennium, Journal of Organizational Behavior 23 (2002), 363-382.

[31] E. Spector, Method variance in organizational research. Truth or urban legend?, Organizational Research Methods 9 (2006), 221-232.

[32] K. Tuomi, J. Ilmarinen, J. Seitsamo, P. Huuhtanen, R. Martikainen, C.H. Nygard and M. Klockars, Summary of the Finnish research project (1981-1992) to promote the health and work ability of aging workers, Scand J Work Environ Health 23 Suppl 1 (1997), 66-71.

[33] T.I.J. van den Berg, L.A.M. Elders, B.C.H. de Zwart and A. Burdorf, The effects of work-related and individual factors on the Work Ability Index: a systematic review, Occupational and Environmental Medicine 66 (2009), 211-220.

[34] M. van der Doef and S. Maes, The Job Demand-Control (Support) model and psychological well-being: A review of 20 years of empirical research, Work \& Stress 13 (1999), 87-114. 
[35] T.D. Wall, P.R. Jackson and S. Mullarkey, Further Evidence on Some New Measures of Job Control, Cognitive Demand and Production Responsibility, Journal of Organizational Behavior 16 (1995), 431-455.

[36] M. Weigl, S. Hornung, S.K. Parker, R. Petru, J. Glaser and P. Angerer, Work engagement and accumulation of task, social, personal resources: A three-wave structural equation model, Journal of Vocational Behavior 77 (2010), 140-153.

[37] B.S. Wiese, A.M. Freund and P.B. Baltes, Selection, optimization, and compensation: An action-related approach to work and partnership, Journal of Vocational Behavior 57 (2000), 273.

[38] B.S. Wiese, A.M. Freund and P.B. Baltes, Subjective career success and emotional well-being: Longitudinal predictive power of selection, optimization and compensation, Journal of Vocational Behavior 60 (2002), 321-335.

[39] D.Y. Yeung and H.H. Fung, Aging and work: How do SOC strategies contribute to job performance across adulthood? Psychology and Aging 24 (2009), 927-940.

[40] L.M. Young, B.B. Baltes and A.K. Pratt, Using selection, optimization, and compensation to reduce job/family stressors: Effective when it matters, Journal of Business and Psychology 21 (2007), 511-539.

[41] H. Zacher and M. Frese, Maintaining a focus on opportunities at work: The interplay between age, job complexity, and the use of selection, optimization, and compensation strategies, Journal of Organizational Behavior 32 (2011), 291318.

[42] D. Zapf, C. Dormann and M. Frese, Longitudinal studies in organizational stress research: A review of the literature with reference to methodological isssues, Journal of Occupational Health Psychology 1 (1996), 145-169. 